\title{
The Expression of Beclin-1 in Hepatocellular Carcinoma and Non-Tumor Liver Tissue: A Meta-Analysis
}

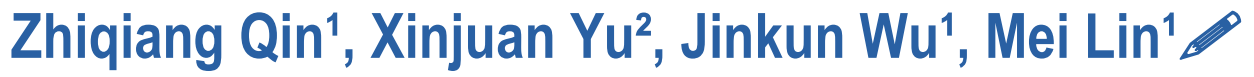

\author{
${ }^{1}$ Department of Pathology, School of Basic Medicine, Medical College, Qingdao University, Qingdao, Shandong \\ 266071, China \\ ${ }^{2}$ Central Laboratories, Qingdao Municipal Hospital, Qingdao, Shandong 266071, China
}

\begin{abstract}
Background Recently, Beclin-1 expression in hepatocellular carcinoma (HCC) and non-tumor liver tissue have been investigated by several studies. However, the results are controversial. The aim of this study was to clarify the role of Beclin-1 in the occurrence of HCC by comparing the difference of Beclin-1 expression between HCC and non-tumor liver tissue. Methods An electronic retrieve for relevant studies was performed in PubMed, EMBASE, China National Knowledge Infrastructure (CNKI), Wan Fang and Chinese VIP databases updated to December 31, 2017. Newcastle-Ottawa-Scale (NOS) was used to assess the quality of the eligible studies. Sensitivity, subgroup, and publication bias analyses were also carried out in this meta-analysis. Statistical analysis was performed by Review Manager 5.3 and STATA 12.0. Results Six high-quality studies with 357 HCC patients were eligible. There was no significant difference of Beclin-1 expression between HCC and non-tumor liver tissue $(\mathrm{OR}=2.48,95 \% \mathrm{CI}=0.64-9.58, \mathrm{P}=0.19)$. However, sensitivity analysis showed that Beclin-1 was lower in HCC than in non-tumor liver tissue after omitting Kang et al.'s study $(\mathrm{OR}=4.14,95 \% \mathrm{CI}=1.75-9.81, \mathrm{P}=0.001)$, and heterogeneity was not evident $\left(\mathrm{P}=0.14, \mathrm{I}^{2}=43 \%\right)$. Subgroup analysis suggested that heterogeneity may stem from ethnicity. The funnel plot and Egger's test $(\mathrm{P}=0.900)$ demonstrated that no significant publication bias was present in this meta-analysis. Conclusion This meta-analysis indicated that there was no significant difference of Beclin-1 expression between HCC and non-tumor liver tissue.
\end{abstract}

Keywords: Beclin-1, Hepatocellular Carcinoma (HCC), Non-Tumor Liver Tissue, Meta-Analysis, Autophagy

\section{Introduction}

Hepatocellular carcinoma (HCC) is the most frequent type of primary liver cancer and has been a significant health problem worldwide due to its high mortality [1]. Currently, it is generally accepted that hepatitis B/C virus infection, usage of alcohol and aflatoxin B1 exposure are the main risk factors [2]. Since the symptoms of early-stage HCC are atypical, most patients present with metastasis at diagnosis. Therefore the prognosis for HCC patients was poor [3].

This article is published under the terms of the Creative Commons Attribution License 4.0

Author(s) retain the copyright of this article. Publication rights with Alkhaer Publications.

Published at: http://www.ijsciences.com/pub/issue/2018-04/

DOI: 10.18483/ijSci.1625; Online ISSN: 2305-3925; Print ISSN: 2410-4477 
Autophagy is a metabolic process in which cell components are degraded by lysosomes, thereby maintaining intracellular homeostasis. It is a highly-conserved process regulated by a specific series of autophagy genes (Atg genes) including Atg6 [4]. Beclin-1, mammalian homologue of yeast Atg6, plays an essential role in the regulation of autophagy [5]. Beclin-1 was initially thought to be a tumor suppressor. This viewpoint derived from previous reports that Belin-1 was monoallelically deleted in human prostate, breast and ovarian cancers and was expressed at decreased level in these tumors [6]. The expression of Beclin-1 in HCC has been studied for more than a decade, but controversial results have been obtained. Qiu et al. [7] found that a significantly low Beclin-1 expression was presented in HCC tissues compared with adjacent non-tumor tissues and Beclin-1 may inhibit tumorigenesis. However, Kang et al. [8] found that there was less Beclin-1 expression in normal liver tissues than that in HCC tissues.

Hence, a meta-analysis investigating the difference of Beclin-1 expression in HCC and non-tumor liver tissue was performed.

\section{MATERIAL AND METHODS}

\section{Search strategy}

This meta-analysis was conducted in accordance with the Preferred Reporting Items for Systematic Reviews and Meta-Analyses (PRISMA) guidelines [9]. PubMed, EMBASE, China National Knowledge Infrastructure (CNKI), Wan Fang and Chinese VIP were searched systematically to identify studies from initial to December 31, 2017. Searches included the terms "Beclin-1" OR "beclin 1" OR "BECN1" OR "ATG6" AND "hepatocellular" OR "liver" OR "hepatic" AND “carcinoma" OR "tumor" OR "neoplasm" OR “cancer". In addition, the reference lists of relevant reviews and the included literatures were retrieved manually for eligibility.

\section{Criteria for inclusion and exclusion}

The criteria for inclusion of eligible studies in this meta-analysis were: (1) English or Chinese studies and full texts were available; (2) case-control studies; (3) HCC tissue and non-tumor liver tissue were pathologically confirmed; (4) Beclin-1 expression in HCC and non-tumor liver tissue were reported; (5) data was available to obtain the odds ratio (OR) and $95 \%$ confidence interval (CI).

Exclusion criteria were as follows: (1) duplicate publication; (2) non-original studies, such as reviews, conference abstracts, case reports, editorials or comments; (3) Beclin-1 expression was not tested by immunohistochemistry (IHC); (4) focused on animal models or cancer cell lines.

\section{Data extraction and quality assessment}

Two reviewers (Zhiqiang Qin and Xinjuan Yu) separately extracted data from the included studies. Discrepancies in data extraction were resolved by consensus with a third investigator (Mei Lin). For each study, the following data was extracted: first author, publication year, country, HCC patients' characteristics (number, gender, age range, percentage of Beclin-1 low expression) and detection method of Beclin-1.

The Newcastle-Ottawa-Scale (NOS) was recommended to evaluate the quality of the included studies [10]. Studies scored $\geq 6$ were graded as high-quality [11].

\section{Statistical analysis}

This meta-analysis was performed by using Review Manager 5.3 (Cochrane Collaboration, Oxford, UK) and STATA 12.0 (StataCorp, College Station, TX, USA). Pooled OR with $95 \%$ CI was used to evaluate the difference of Beclin-1 expression in different liver tissues (HCC/non-tumor liver tissue). Heterogeneity was assessed by chi-squared test ( $\mathrm{Q}$ test) and $\mathrm{I}^{2}$ test. If heterogeneity was no significant $\left(\mathrm{P}>0.1\right.$ or $\left.\mathrm{I}^{2} \leq 50 \%\right)$, fixed-effect model was used. Otherwise, random-effect model was selected. Subgroup analysis and sensitivity 
analysis were used to explore sources of heterogeneity.

Publication bias was evaluated by funnel plot and Egger's test. $\mathrm{P}<0.05$ was considered statistically significant.

\section{RESULTS}

\section{Selection of included studies}

The flow diagram of selection steps is displayed in Figure 1. A total of 668 potential studies were initially identified on the basis of our defined criteria. 203 repeated documents, 131 non-original studies, 118 studies irrelevant to HCC or Beclin-1, and 189 studies on animal or cell lines were excluded. The remaining 27 studies were further assessed by reading full text, and then 21 studies were removed due to not meet the selection criteria. Finally, 6 eligible articles containing 357 HCC patients were included in this meta-analysis.
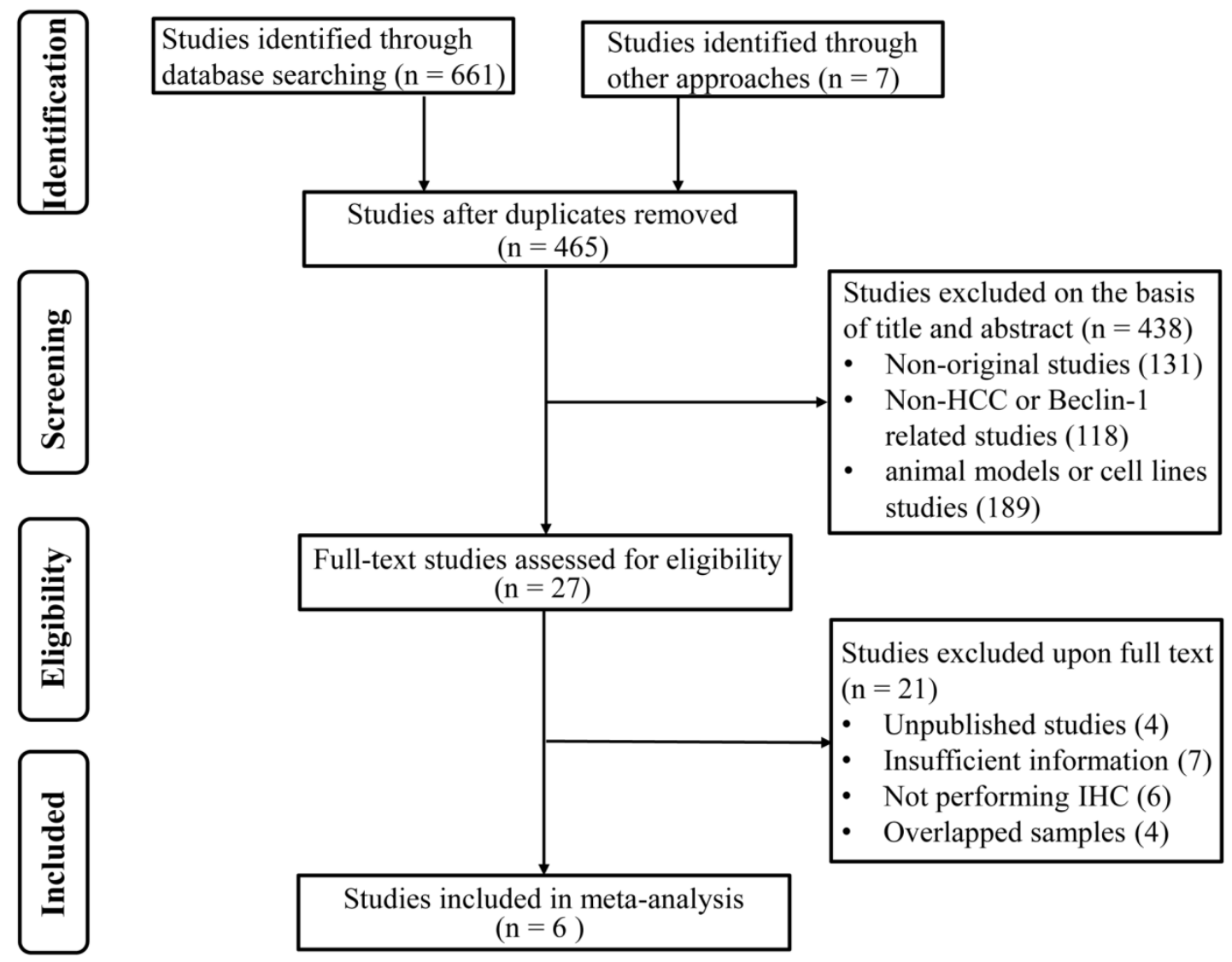

Figure 1. Flow chart of study selection.

\section{Studies characteristics and quality assessment}

Of the 6 included studies, 4 studies [7, 8, 12, 13] were published in English and the other 2 studies [14, 15] were in Chinese. The publication years were from 2013 to 2016 and HCC sample sizes ranged from 35 to 103 . All HCC patients have proven pathological diagnosis. Among the 6 eligible studies, 4 studies [7, 8, 14, 15] originated from China and the other 2 studies [12, 13] were from Egypt. IHC staining was used for investigation of Beclin-1 expression in all the studies. The percentage of reduced Beclin-1 expression in HCC ranged from $18.52 \%$ to $78.64 \%$. The characteristics of eligible studies are listed in Table 1.

As shown in Tables 2, the quality of the included studies was evaluated by NOS, and all of these studies were high quality studies. 
The Expression of Beclin-1 in Hepatocellular Carcinoma and Non-Tumor Liver Tissue: A Meta-Analysis

Table 1. Characteristics of the included studies

\begin{tabular}{lllllll}
\hline References & Country & $\begin{array}{l}\text { No. of HCC } \\
\text { patients }\end{array}$ & $\begin{array}{l}\text { Gender } \\
(\mathrm{M} / \mathrm{F}, \mathrm{n})\end{array}$ & $\begin{array}{l}\text { Age range } \\
(\text { year })\end{array}$ & $\begin{array}{l}\text { Low Beclin-1 } \\
\text { expression (\%) }\end{array}$ & Method \\
\hline Kang 2013 [8] & China & 50 & $47 / 3$ & $28-71$ & $11 / 50(22.00)$ & IHC \\
Guo 2013 [14] & China & 54 & $39 / 15$ & $33-75$ & $10 / 54(18.52)$ & IHC \\
Qiu 2014 [7] & China & 103 & $85 / 18$ & $21-79$ & $81 / 103(78.64)$ & IHC \\
Osman 2015 [12] & Egypt & 65 & $51 / 14$ & $40-74$ & $32 / 65(49.23)$ & IHC \\
Yang 2015 [15] & China & 50 & $39 / 11$ & $26-74$ & $11 / 50(22.00)$ & IHC \\
Al-Shenawy 2016 [13] & Egypt & 35 & $20 / 15$ & $23-75$ & $18 / 35(51.43)$ & IHC \\
\hline
\end{tabular}

M: male; F: female; IHC: immunohistochemistry

Table 2. Newcastle-Ottawa Quality Assessment Scale (case control studies)

\begin{tabular}{|c|c|c|c|c|c|c|c|c|c|}
\hline \multirow[t]{2}{*}{ Study } & \multicolumn{4}{|c|}{ Selection } & \multirow{2}{*}{$\begin{array}{l}\text { Comparability } \\
\text { Basis of design } \\
\text { or analysis }\end{array}$} & \multicolumn{3}{|c|}{ Exposure } & \multirow{2}{*}{$\begin{array}{l}\text { Total } \\
\text { score }\end{array}$} \\
\hline & $\begin{array}{l}\text { Case definition } \\
\text { adequate }\end{array}$ & $\begin{array}{l}\text { Representativeness } \\
\text { of the cases }\end{array}$ & $\begin{array}{l}\text { Selection of } \\
\text { controls }\end{array}$ & $\begin{array}{l}\text { Definition of } \\
\text { controls }\end{array}$ & & $\begin{array}{l}\text { Ascertainment } \\
\text { of exposure }\end{array}$ & $\begin{array}{l}\text { Same method of } \\
\text { ascertainment }\end{array}$ & $\begin{array}{l}\text { Non-response } \\
\text { rate }\end{array}$ & \\
\hline Kang 2013 [8] & 1 & 1 & 0 & 1 & 1 & 1 & 1 & 1 & 7 \\
\hline Guo 2013 [14] & 1 & 1 & 1 & 1 & 2 & 1 & 1 & 1 & 9 \\
\hline Qiu 2014 [7] & 1 & 1 & 1 & 1 & 1 & 1 & 1 & 1 & 8 \\
\hline Osman 2015 [12] & 1 & 1 & 1 & 1 & 2 & 1 & 1 & 1 & 9 \\
\hline Yang 2015 [15] & 1 & 1 & 0 & 1 & 1 & 1 & 1 & 1 & 7 \\
\hline Al-Shenawy 2016 [13] & 1 & 1 & 0 & 0 & 1 & 1 & 1 & 1 & 6 \\
\hline
\end{tabular}

A study can be awarded a maximum of one score for each numbered item within the Selection and Exposure

Beclin-1 expression in HCC and non-tumor liver tissue

categories. A maximum of two scores can be given for Comparability.

http://www.ohri.ca/programs/clinical_epidemiology/ox ford.htm
As shown in Figure 2, there was no significant difference in Beclin-1 expression between $\mathrm{HCC}$ and non-tumor liver tissue $(\mathrm{OR}=2.48,95 \% \mathrm{CI}=0.64-9.58$, $\mathrm{P}=0.19)$. However, remarkable heterogeneity was observed $\left(\mathrm{P}=0.0004, \mathrm{I}^{2}=78 \%\right)$.

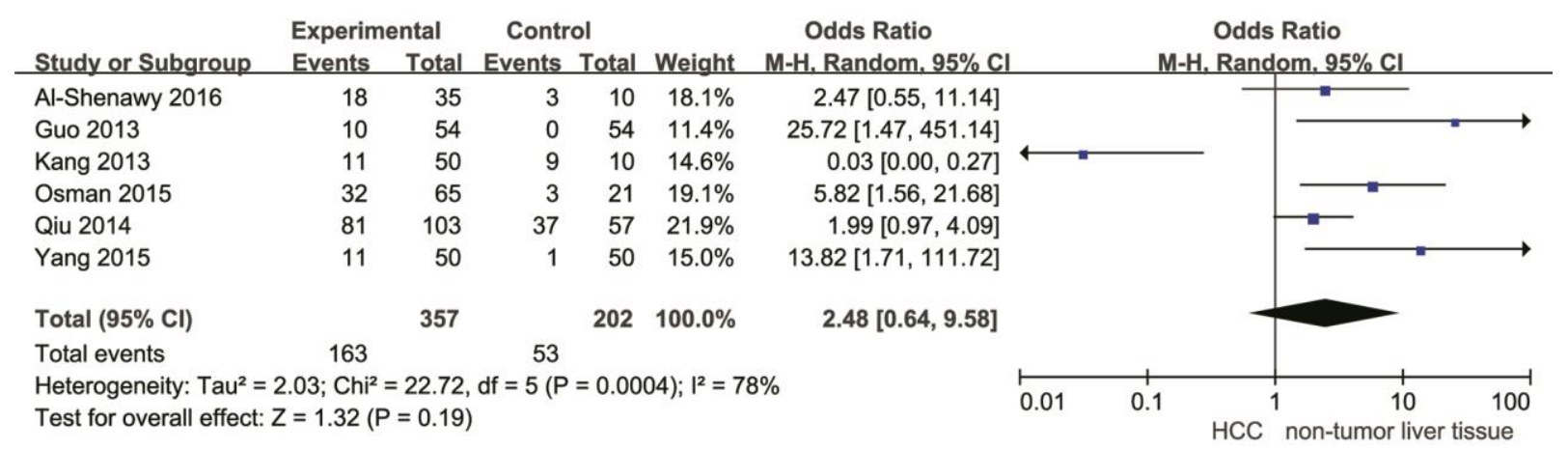

Figure 2. Forest plot of studies evaluating the difference between Beclin-1 expression in HCC and non-tumor liver tissue.

\section{Sensitivity analysis}

Sensitivity analysis was performed by omitting 1 study per time in turn. As shown in Tables 3, the difference of Beclin-1 expression in HCC and non-tumor liver tissue was affected by Kang et al.'s study [8]. After omitting this study, Beclin-1 was low in HCC compared with that of non-tumor liver tissue $(\mathrm{OR}=$ $4.14,95 \% \mathrm{CI}=1.75-9.81, \mathrm{P}=0.001)$ and heterogeneity was not evident $\left(\mathrm{P}=0.14, \mathrm{I}^{2}=43 \%\right)$. 
The Expression of Beclin-1 in Hepatocellular Carcinoma and Non-Tumor Liver Tissue: A Meta-Analysis

Table 3. Sensitivity analysis for Beclin-1 expression in different liver tissues

\begin{tabular}{lll}
\hline Study omitted & OR $(95 \%$ CI $)$ & P \\
\hline Kang 2013 [8] & $4.14(1.75-9.81)$ & 0.001 \\
Guo 2013 [14] & $1.84(0.44-7.66)$ & 0.40 \\
Qiu 2014 [7] & $2.66(0.37-19.40)$ & 0.33 \\
Osman 2015 [12] & $2.05(0.38-11.05)$ & 0.40 \\
Yang 2015 [15] & $1.83(0.42-8.07)$ & 0.42 \\
Al-Shenawy 2016 [13] & $2.50(0.46-13.64)$ & 0.29 \\
Combined & $2.48(0.64-9.58)$ & 0.19 \\
\hline
\end{tabular}

\section{Subgroup analysis}

As shown in Table 4, subgroup analysis was conducted by histologic type of non-tumor liver tissue and ethnicity. Non-tumor liver tissue samples were adjacent non-tumor liver tissues (ANT) in 3 studies [7, 12, 14], while the remaining 3 studies were normal liver tissues (non-ANT) including previously healthy donors, normal liver biopsy samples operated for liver metastases and trauma $[8,13,15]$. Beclin-1 expression was lower in $\mathrm{HCC}$ than that in ANT $(\mathrm{OR}=4.19,95 \%$ $\mathrm{CI}=1.23-14.35, \mathrm{P}=0.02)$ with obvious heterogeneity $\left(\mathrm{P}=0.10, \mathrm{I}^{2}=58 \%\right)$. While Beclin-1 expression in
HCC was not different from normal liver tissues $(\mathrm{OR}=$ 1.06, 95\% CI $=0.04-26.30, \mathrm{P}=0.97)$ and the heterogeneity was obvious $\left(\mathrm{P}=0.0002, \mathrm{I}^{2}=88 \%\right)$. As for the ethnicity, Beclin-1 was lower in HCC than that in non-tumor liver tissue among Caucasians $(\mathrm{OR}=$ $4.02,95 \% \mathrm{CI}=1.49-10.82, \mathrm{P}=0.006$ ) with no heterogeneity $\left(\mathrm{P}=0.40, \mathrm{I}^{2}=0 \%\right)$. In contrast, Beclin-1 expression in HCC and non-tumor liver tissue among Asians showed no significant difference $(O R=2.01$, $95 \% \mathrm{CI}=0.19-21.37, \mathrm{P}=0.56)$ and the heterogeneity was evident $\left(\mathrm{P}=0.0001, \mathrm{I}^{2}=85 \%\right)$.

Table 4. Subgroup analysis of Beclin-1 expression in different liver tissues

\begin{tabular}{|c|c|c|c|c|c|}
\hline \multirow[t]{2}{*}{ Subgroups } & \multirow{2}{*}{$\begin{array}{l}\text { No. of } \\
\text { studies }\end{array}$} & \multirow[t]{2}{*}{ Pooled OR (95\% CI) } & \multirow[t]{2}{*}{$\mathrm{P}$} & \multicolumn{2}{|c|}{ Heterogeneity } \\
\hline & & & & $\mathrm{I}^{2}$ & $\mathrm{P}$ \\
\hline \multicolumn{6}{|l|}{ Histologic type } \\
\hline ANT & 3 & $4.19(1.23-14.35)$ & 0.02 & $58 \%$ & 0.10 \\
\hline Non-ANT & 3 & $1.06(0.04-26.30)$ & 0.97 & $88 \%$ & 0.0002 \\
\hline \multicolumn{6}{|l|}{ Ethnicity } \\
\hline Asians & 4 & $2.01(0.19-21.37)$ & 0.56 & $85 \%$ & 0.0001 \\
\hline Caucasians & 2 & $4.02(1.49-10.82)$ & 0.006 & $0 \%$ & 0.40 \\
\hline
\end{tabular}

ANT: adjacent non-tumor tissues; Non-ANT: normal liver tissues

\section{Publication bias}

As shown in Figure 3, funnel plot did not reveal evidence of significant asymmetry in this study. The result was further affirmed by Egger's test $(\mathrm{P}=0.900)$. 


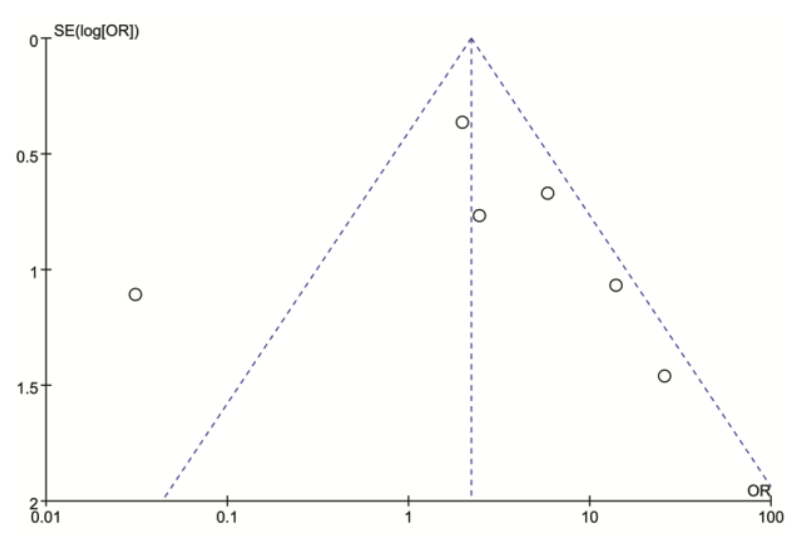

Figure 3. Funnel plot for publication bias.

\section{DISCUSSION}

Currently, it is generally recognized that autophagy is closely linked to a variety of diverse pathologies [16]. Research showed that autophagy may suppress tumorigenesis by protecting the stability of chromosomes and limiting metabolic stress [17]. Beclin-1, an autophagy-related protein, has been found crucial for tumorigenesis [18]. However, the effect of Beclin-1 in the occurrence of HCC is controversial and no meta-analysis is available now. Therefore, we conducted a meta-analysis to clarify the role of Beclin-1 in the carcinogenesis of HCC.

In this meta-analysis, 6 articles with $357 \mathrm{HCC}$ patients meet the inclusion criterion. Result showed that Beclin-1 expression was not different between HCC and non-tumor liver tissue and the heterogeneity was evident. Therefore, we performed sensitivity analysis and subgroup analysis to explore the sources of heterogeneity. In the sensitivity analysis, Beclin-1 was lower in $\mathrm{HCC}$ than that in non-tumor liver tissue after removing Kang et al.'s study [8] and heterogeneity was decreased. The HCC group consisted of 47 male and 3 female in this study. The proportion of female $(6.00 \%)$ is much lower than other included study $(17.48-42.86 \%)$. So we conferred that sex ratio of samples may affect Beclin-1 expression and cause the significant heterogeneity. In subgroup analysis, Beclin-1 was lower in HCC than that in adjacent non-tumor liver tissue. This result indicated that low expression of Beclin-1, or autophagy defect, may contribute to the tumorigenesis. However, the heterogeneity was still obvious. Subgroup analysis also conducted according to ethnicity and result showed that Beclin-1 was lower in HCC than that in non-tumor liver tissue among Caucasians. This analysis showed no heterogeneity. Thus, we speculated that heterogeneity in the study stemed from ethnicity.

It should be noted that there are several limitations in our meta-analysis. First, articles with positive results are more tended to be published, which may potentially bring publication bias. Second, heterogeneity is a concern. Despite IHC is the only way to detect Beclin-1 expression in all included studies, the judgment standard and cut-off value of Beclin-1 expression was not uniform.

In this meta-analysis, we found that there was no significant difference in Beclin-1 expression between HCC and non-tumor liver tissue.

\section{REFERENCES}

1. Forner, A., M. Reig, and J. Bruix, Hepatocellular carcinoma. Lancet (London, England), 2018.

2. Mathew, S., et al., Biomarkers for virus-induced hepatocellular carcinoma (HCC). Infection, genetics and evolution : journal of molecular epidemiology and evolutionary genetics in infectious diseases, 2014. 26: p. 327-39.

3. Gomaa, A.I. and I. Waked, Recent advances in multidisciplinary management of hepatocellular carcinoma. World journal of hepatology, 2015. 7(4): p. 673-87.

4. Eskelinen, E.L. and P. Saftig, Autophagy: a lysosomal degradation pathway with a central role in health and disease. Biochimica et biophysica acta, 2009. 1793(4): p. 664-73.

5. Brech, A., et al., Autophagy in tumour suppression and promotion. Molecular oncology, 2009. 3(4): p. 366-75.

6. White, E., The role for autophagy in cancer. The Journal of clinical investigation, 2015. 125(1): p. 42-6.

7. Qiu, D.M., et al., The expression of beclin-1, an autophagic gene, in hepatocellular carcinoma associated with clinical pathological and prognostic significance. BMC Cancer, 2014. 
The Expression of Beclin-1 in Hepatocellular Carcinoma and Non-Tumor Liver Tissue: A Meta-Analysis

14: p. 327.

8. Kang, K.F., et al., Beclin 1 and nuclear factor-kappaBp65 are upregulated in hepatocellular carcinoma. Oncol Lett, 2013. 5(6) p. 1813-1818.

9. Moher, D., et al., Preferred reporting items for systematic reviews and meta-analyses: the PRISMA statement. Annals of internal medicine, 2009. 151(4): p. 264-9, w64.

10. Stang, A., Critical evaluation of the Newcastle-Ottawa scale for the assessment of the quality of nonrandomized studies in meta-analyses. European journal of epidemiology, 2010. 25(9): p. 603-5.

11. Liang, C., et al., Prognostic and clinicopathological value of Nanog in hepatocellular carcinoma: A meta-analysis. Clinica chimica acta; international journal of clinical chemistry, 2018. 477: p. 24-31.

12. Osman, N.A., D.M. Abd El-Rehim, and I.M. Kamal, Defective Beclin-1 and elevated hypoxia-inducible factor (HIF)-1alpha expression are closely linked to tumorigenesis, differentiation, and progression of hepatocellular carcinoma. Tumour Biol, 2015. 36(6): p. 4293-9.

13. Al-Shenawy, H.A., Expression of Beclin-1, an autophagy-related marker, in chronic hepatitis and hepatocellular carcinoma and its relation with apoptotic markers. APMIS, 2016. 124(3): p. 229-37.

14. Guo, X.D., et al., Expression and Clinical Significance of Beclin 1 in Patients with Hepatocellular Carcinoma. Progress in Modern Biomedicine, 2013. 13(1): p. 85-87.

15. Yang, W., et al., Expression of Beclin1 in Human Hepatocellular Carcinoma and Effects of TGF- $\beta$ on Proliferation of Hepatocellular Carcinoma Cells. Int J Lab Med, 2015. 36(1): p. 108-109.

16. Levine, B. and G. Kroemer, Autophagy in the pathogenesis of disease. Cell, 2008. 132(1): p. 27-42.

17. Mathew, R., et al., Autophagy suppresses tumor progression by limiting chromosomal instability. Genes \& development, 2007. 21(11): p. 1367-81.

18. Yue, Z., et al., Beclin 1, an autophagy gene essential for early embryonic development, is a haploinsufficient tumor suppressor. Proceedings of the National Academy of Sciences of the United States of America, 2003. 100(25): p. 15077-82. 